\title{
Empoderamento de usuários e familiares em saúde mental e em pesquisa avaliativa/interventiva: uma breve comparação entre a tradição anglo-saxônica e a experiência brasileira
}

\author{
Empowerment of users and family members in mental health care \\ and in evaluative/interventional research: a brief comparison \\ between the Anglo-Saxon tradition and the Brazilian experience
}

Eduardo Mourão Vasconcelos ${ }^{1}$

${ }^{1}$ Departamento de Métodos e Técnicas, Escola de Serviço Social, UFRJ. Av Pasteur 250 Fundos, Botafogo. 22.290-240 Rio de Janeiro RJ.

emvasconcelos55@gmail.com

\begin{abstract}
The scope of this article is to assess the main characteristics of the traditions and experiences of empowerment of users and family members in mental health treatment and services in Anglo-Saxon countries and in Brazil and the repercussions and strategies thereof in the field of evaluative and interventional research in mental health. Based on a brief bibliographical review of the literature, the aim is to compare how the empowerment tradition has developed in the two realities, based on the characteristics of the econom$i c$, political, social - and especially cultural - context. The review revealed how these contexts induce different perspectives on how to foster the autonomy and empowerment of users and family members in social policies and mental health, as well as their appropriation in the field of evaluative and interventional research. In Anglo-Saxon countries, this tradition has been vigorously promoted over the past four decades, and in Brazil the participative strategies emphasize mixed mechanisms - professionals, users and family members together - with the dominant presence of the professionals. The strategies in Brazil more directly designed for users and family members are recent and have been implemented from 2005 onwards. Key words Mental health, Empowerment, Autonomy, Evaluative research, Interventional research
\end{abstract}

Resumo O objeto deste artigo são as principais características das tradições e experiências de empoderamento de usuários e familiares em abordagens e serviços de saúde mental em países anglosaxônicos e no Brasil, e suas repercussões e estratégias no campo da pesquisa avaliativa e interventiva em saúde mental. O objetivo é comparar, através de uma breve revisão bibliográfica da literatura, como as tradições de empoderamento se desenvolveram nos dois cenários, a partir de características do contexto econômico, político, social e particularmente cultural. A revisão mostrou como estes contextos geram diferentes perspectivas de valorização da autonomização e empoderamento de usuários e familiares nas politicas sociais em geral e em saúde mental, como também nas apropriações no campo da pesquisa avaliativa e interventiva em saúde mental. Nos países anglo-saxônicos, esta tradição vem se desenvolvendo fortemente há cerca de 4 décadas, e no Brasil as estratégias participacionistas enfatizam mecanismos mistos - profissionais, usuários e familiares juntos -, com a presença dominante dos profissionais, e as iniciativas mais diretamente desenhadas para os usuários e familiares são muito recentes, a partir de 2005.

Palavras-chave Saúde mental, Empoderamento, Autonomia, Pesquisa avaliativa, Pesquisa interventiva 


\section{Introdução}

Este trabalho visa revisar e comparar as experiências de reforma psiquiátrica e de empoderamento (empowerment) de usuários de serviços e seus familiares em países anglo-saxônicos (com ênfase particular no Reino Unido e nos Estados Unidos) e no Brasil, e suas repercussões no campo da pesquisa avaliativa e interventiva em saúde mental. O trabalho objetiva, primeiramente, identificar aspectos conceituais importantes para uma avaliação e apropriação crítica desta perspectiva, do ponto de vista ético-político das classes populares em países periféricos e semiperiféricos. Em segundo, o artigo busca também identificar como as características históricas, sociais e culturais estruturais, bastante diferenciadas nos dois contextos, acabam gerando perfis muito variados no potencial e na dinâmica concreta de participação, envolvimento e empoderamento de usuários e familiares do campo da saúde mental, bem como em serviços sociais em geral. Na nossa perspectiva, sistematizar estas diferenças é fundamental para a compreensão e avaliação das experiências e projetos piloto hoje no Brasil, a partir da influência que os movimentos de usuários e de reforma psiquiátrica anglo-saxônicos vem ganhando em nosso país. Além disso, ainda que breve e sintética, a revisão das conquistas e desafios no campo da pesquisa avaliativa e interventiva em saúde mental comprometida com o empoderamento, nos países anglo-saxônicos, nos permite no Brasil visualizar um campo plenamente desenvolvido, vasto, fértil e variado de estratégias possíveis que podem ser apropriadas em pesquisa em saúde mental, com seus desafios, para estimular a investigação acadêmica e de avaliação engajada com a reforma psiquiátrica e o movimento antimanicomial em nosso país. E por último, este artigo visa também subsidiar alguns projetos piloto já em andamento no Brasil, de experimentação e sistematização de dispositivos de empoderamento em saúde mental, integrados à pesquisa ou com estratégias participativas de produção de conhecimento e avaliação, inspiradas nos princípios do empoderamento. Entretanto, dado o formato enxuto dos artigos neste periódico, esse último objetivo será cumprido em outro artigo nesta coletânea, coletivo, para o qual convidamos desde já o leitor interessado no tema.

\section{Contexto histórico e conceitual dos processos de reforma psiquiátrica e de empoderamento em saúde mental em países anglo-saxônicos e no Brasil}

\section{Os processos de reforma psiquiátrica e a participação de usuários de serviços e seus familiares}

Durante e após a II Guerra Mundial, nos países de capitalismo central, o esforço de reabilitação de militares e civis marcados pela guerra, o ambiente econômico e social de reconstrução e de revalorização da força de trabalho, o processo de redemocratização, bem como o desenvolvimento de políticas públicas de bem estar social, levaram a conquistas significativas dos direitos clássicos de cidadania, particularmente no campo dos direitos civis e sociais. Este contexto estimulou processos de reforma psiquiátrica ${ }^{1}$, cujo objetivo central tem sido a substituição da internação em instituições do tipo manicomial, para serviços abertos, de base territorial, perto dos locais de moradia, e visando a reinserção de seus usuários na vida social mais ampla. Além disso, visam também transformar as relações sociais baseadas na discriminação e segregação das pessoas com transtorno mental, com iniciativas ativas na esfera cultural, artística, educacional e de participação na sociedade em geral. Em outras palavras, se coloca a questão de como se pode avançar na esfera das práticas micropolíticas, do nivel de participação social, das relações de poder e das representações sociais e culturais difusas, nas suas relações com o campo da saúde mental.

Neste terreno, os movimentos sociais de usuários e familiares da saúde mental de vários países, particularmente a partir da década de 1970, apresentam novos insights e conquistas importantes para os processos de reforma psiquiátrica. Estes atores sociais representam os principais receptores dos serviços de saúde mental e potenciais interessados em mudanças mais profundas nas políticas e sistemas convencionais de saúde mental, bem como na cultura difusa na sociedade em relação a eles e ao tema. Em muitos países, eles não só desenvolvem ações próprias e autônomas, como também forçam serviços e programas a darem respostas mais adequadas a suas necessidades, além de criarem novos conceitos e abordagens teóricas. Nos países do Norte da Europa e de cultura anglo-saxônica, as abordagens e as estratégias de empoderamento constituem a principal perspectiva conceitual e prático-operativa nesta direção. 
Os processos de reforma psiquiátrica se difundiram em países periféricos e semiperiféricos, como o Brasil, a partir da década de $1980^{1-3}$, mas com características próprias no campo das políticas sociais, dos movimentos sociais e da cultura, gerando especificidades no processo de transformação dos serviços, das representações que sustentam a discriminação e estigma, bem como na concepção e nas estratégias de empoderamento em saúde mental, como veremos a seguir.

\section{O empoderamento}

\section{no campo da saúde mental,} suas ambiguidades conceituais e desafios

Vasconcelos $^{4}$ propõe uma primeira aproximação ao conceito na seguinte definição provisória: Aumento do poder e autonomia pessoal e coletiva de indivíduos e grupos sociais nas relações interpessoais e institutionais, principalmente daqueles submetidos a relações de opressão, dominação e discriminação social. A apropriação do conceito para o contexto brasileiro nos permitiu identificar diferentes níveis de práticas e estratégias de empoderamento em saúde mental: o cuidado de si, a ajuda mútua, o suporte mútuo, a transformação da cultura difusa em relação ao transtorno mental na sociedade, a defesa de direitos, a militância social e política ${ }^{4}$, e o uso de narrativas pessoais de experiência de vida em primeira pessoa ${ }^{5}$. Por razões de economia, a explicitação destas estratégias não pode ser realizada aqui, mas está disponível na literatura indicada.

Entretanto, não se trata de um conceito com estatuto teórico e ético-político próprio. Em nossa visão, constitui uma interpelação de caráter polissêmico, similar às de participação e humanização, que pode ser apropriada tanto para fins conservadores quanto emancipatórios. Em outro trabalho de revisão ${ }^{4}$, procuramos mostrar como, na história ocidental desde a modernidade, a ideia e as práticas de empoderamento foram apropriadas em ambas as direções. Alguns exemplos:

a) Do lado conservador, temos a cultura de autoajuda (self-help) desde o século XIX, como o movimento de temperança nos países anglo-saxônicos, e seus desdobramentos até hoje, como na literatura atual de autoajuda, associada ao liberalismo radical, individualização, recalque da dimensão coletiva dos problemas sociais e individuais, pragmatismo e utilitarismo, que visam predominantemente adaptar os indivíduos ao status quo e ao bom cumprimento das expectativas sociais práticas (expresso, por exemplo, na expressão "alcançar o sucesso"). Mais recentemente, o Banco Mundial se apropriou de forma mais sofisticada desta interpelação, para pregar estratégias participativas de desenvolvimento lo$\mathrm{cal}^{6}$, sem questionar as suas bases mais amplas de pauperização econômica e social, fortemente estimuladas pelas atuais políticas capitalistas de reajuste neoliberal.

b) $\mathrm{Na}$ direção emancipatória, temos como exemplo recente os vários movimentos e organizações de trabalhadores, de direitos civis e de minorias étnicas, o movimento feminista, etc. No Brasil, durante a ditadura militar, tivemos vários movimentos sociais populares com forte perspectiva de empoderamento de seus membros, como as Comunidades Eclesiais de Base (CEB), inspiradas na Teologia da Libertação; a educação popular de Paulo Freire e seus desdobramentos; e, mais recentemente, os próprios dispositivos de controle social das políticas sociais, como em nosso sistema de saúde atual. A maioria destes casos constituem abordagens educativas e de trabalho de base com as populações e grupos oprimidos, ou estratégias ligadas a políticas sociais, que precisam ser inseridas em projetos e teorias emancipatórias mais amplas e totalizadoras.

Particularmente na literatura anglo-saxônica, a interpelação de empoderamento muitas vezes é apresentada como única ou principal direção ética e política de categorias profissionais e de agências governamentais, sem outras qualificações, como um consenso possível, sem enfrentamentos ou questionamentos à mentalidade socialdemocrata hegemônica, particularmente no Reino Unido ${ }^{4}$. Além disso, não explicitam um posicionamento mais claro em relação ao modelo econômico e social vigente e às características das políticas sociais que deveriam ser priorizadas pelos atores sociais e políticos mais comprometidos do campo.

Assim, nossa visão é de que a interpelação e as estratégias de empoderamento podem e devem ser apropriadas para fins emancipatórios, mas isso requer:

- reconhecer seu caráter polissêmico;

- conhecer minimamente sua história anterior de apropriações conservadoras e emancipatórias;

- identificar e avaliar criticamente as suas apropriações recentes pelas forças sociais e políticas hegemônicas, buscando se diferenciar e superar os limites ideológicos e políticos em que a interpelação é enclausurada;

- reconhecer que as abordagens e estratégias de empoderamento não são suficientes e susten- 
táveis por si mesmas, e ancorá-las em princípios ético-políticos, em teorização política, social, cultural e psicossocial mais consistente, e em políticas sociais e projetos sócio-históricos mais amplos, para poderem se adequar aos interesses emancipatórios e para as características de cada contexto particular;

- admitir que não se trata de fazer simples transposições transnacionais ou transculturais de conceitos e estratégias oriundas de outros países, pois sua apropriação em cada contexto exige revisões conceituais críticas, comparação com as experiências locais já existentes, experiênciaspiloto e sua avaliação, etc., previamente à sua adoção.

\section{Características dos movimentos sociais que sustentam reformas psiquiátricas em países semiperiféricos de origem latina e predominantemente católica}

Os movimentos sociais que sustentam os processos de reforma psiquiátrica têm histórias e características muito heterogêneas nos diversos países e culturas. Na Comunidade Europeia, por exemplo, o perfil destes movimentos, há várias décadas, ainda acompanha uma clássica diferenciação cultural e política ${ }^{4,7}$. Por um lado, temos a Europa mediterrânea de origem latina $e$ com uma história de forte hegemonia católica, com sua cultura mais hierárquica, familiar, comunitária e valorizadora da dependência, e políticas sociais mais enfaticamente estatais. Por outro, na direção norte, temos culturas mais marcadas pelo protestantantismo, individualistas, com laços familiares mais frágeis, e mais valorizadoras da autonomia pessoal, com maior desenvolvimento e participação do chamado Terceiro Setor (Voluntary Sector) em suas politicas sociais, características que se difundiram particularmente nos demais países de língua inglesa. Neste conjunto de países, os usuários constituem um ator social vivo e ativo central nos movimentos sociais em saúde mental, com um perfil mais autonomista e radical em relação aos programas estatais e aos profissionais. Nos países do sul, temos como principal ator os movimentos de profissionais e, secundariamente, de familiares, cujo perfil e valores acompanham os traços principais da cultura hierárquica descrita acima.

Um país semiperiférico como o Brasil apresenta muitas similaridades com os países europeus de origem latina. De modo geral, tendemos a reproduzir os padrões sociais e culturais de nossos colonizadores portugueses, ou seja, a cul- tura latina, católica, familiar e hierárquica, com forte tendência à segregação das classes populares, e políticas públicas fortemente estatais, com forte tendência à burocracia e ao patrimonialismo, e com um desenvolvimento muito mais limitado de programas de bem estar social. Aqui, a cultura hierárquica e patrimonialista foi introduzida já no início da colonização, na concessão pessoal de títulos, de terras e poderes a senhores de terra ligados à Coroa Portuguesa, e se estende como prática político-administrativa hegemônica durante o Império e a República. Neste contexto, uma hierarquia social informal, estruturada em laços e redes personalizadas de influência, constitui o critério prioritário de distribuição de benesses, cargos e direitos, com clara apropriação da esfera pública por redes de interesse privado das elites políticas, econômicas e sociais, e com forte acento burocrático. Na população trabalhadora, esta característica se expressa em uma concepção hierárquica da vida, valorizadora da dependência e dos laços pessoais e familiares, como estratégia de mobilizar suporte social concreto e como forma de ter algum acesso aos limitados benefícios e serviços sociais públicos, em detrimento de formas anônimas e legais de garantia de direitos individuais universais. Esta cultura difusa gera também uma visão muito própria dos fenômenos e do adoecimento mentais, chamada de modelo do nervoso. Para uma visão mais sistemática do tema, é interessante ir a suas principais obras clássicas, nos trabalhos de Faoro ${ }^{8}$, DaMatta $^{9}$ e Duarte ${ }^{10}$.

No entanto, é essencial lembrar que tivemos movimentos sociais muito ativos no processo de luta pela democratização e contra a ditadura militar, cujo governo caiu em 1984, com vertentes bastante organizadas no campo da saúde e saúde mental, induzindo a criação do Sistema Único de Saúde (SUS), formalmente de acesso universal. Tivemos também um movimento antimanicomial, com clara inspiração na experiência italiana, embora mais gradual e lento do que na maioria dos países europeus ${ }^{3,11}$.

Neste processo, há conquistas importantes já consolidadas desde a década de 1980, do ponto de vista da democratização e participação popular. Talvez a principal delas seja a do controle social, pelo qual todas as principais decisões nas políticas de saúde e saúde mental em qualquer nível de gestão (serviços locais, territórios de referência, municípios, estados e união federal), devem passar por conselhos, em que a metade de seus membros devem ser representantes da sociedade civil, particularmente de associações 
civis ligadas ao campo. Há também as conferências nacionais, que permitem a formulação de diretrizes como política de Estado para todo o país, acima de governos específicos.

Entretanto, um conjunto de fatores estruturais, culturais e conjunturais fragilizam a experiência de ativismo e empoderamento nos serviços e na representação da sociedade civil nas instâncias de controle social no país. Entre os principais fatores, podemos indicar aqui:

a) Os movimentos sociais brasileiros de reforma sanitária e psiquiátrica apresentam um perfil similar ao da Europa do sul, ou seja, com predominância e preponderância dos profissionais e dos agentes estatais. Os poucos dados disponíveis sobre a organização de usuários e familiares no país, sistematizados por Vasconce$\operatorname{los}^{3,11,12}$, indicam um crescimento lento do número de associações civis, que em geral são mistas (usuários, familiares e profissionais), e nas quais os últimos têm um papel mais proeminente e regular, em um quadro de organização, bases financeiras e ativismo político em geral bastante fragilizado.

b) A forte hegemonia da cultura patrimonialista e hierárquica produz marcas culturais e políticas profundas e amplas nas classes populares, em todas as esferas de ativismo social e na relação com os profissionais e as instituições de política social, na direção inversa da autonomia e do empoderamento ${ }^{7}$.

c) Em nosso país, a profunda desigualdade social e o mercado de trabalho com quase metade de trabalhadores no setor informal, bem como o perfil dual de oferta de serviços de saúde e saúde mental, também deixam suas marcas. Temos planos e seguros de saúde privados para a elite e para as classes médias, e de outro lado o sistema público que serve às classes populares, de forma muito diferenciada dos programas efetivamente universais de saúde pública europeus e canadense. No Brasil, as classes médias geralmente não frequentam os serviços públicos de atenção psicossocial, nos quais os projetos de empoderamento estão sendo desenvolvidos. Os setores médios, marcados por elitismo, cultura hierárquica e estigma, têm mais dificuldades de assumir uma identidade explícita associada ao transtorno mental. Assim, os potenciais usuários e familiares com maiores recursos educacionais, sociais, econômicos e culturais para o desenvolvimento de um ativismo e uma organização po- lítica mais incisiva e autônoma, não estão disponíveis dentro dos serviços públicos de saúde e saúde mental. E as lideranças oriundas das classes populares têm maiores dificuldades e limitações econômicas, sociais e culturais para se capacitarem e exercerem este ativismo explícito dentro do sistema público de saúde e na sociedade em geral.

d) No contexto atual de políticas neoliberais (subfinanciamento, sucateamento e privatização das políticas sociais e serviços; terceirização, precarização dos direitos e rotatividade do trabalho; e aumento das demandas, do nível de gravidade dos problemas e da população adscrita a cada serviço), as questões do empoderamento acabam sendo secundarizadas pelos trabalhadores de saúde mental.

Em outras palavras, acreditamos que a combinação de todas estas características tendem a dificultar a extensão massiva de estratégias de participação popular e de empoderamento no sistema de políticas sociais e em saúde/saúde mental. A nosso ver, isso não impossibilita as estratégias de empoderamento no país, mas implica que seu significado social, sua dinâmica cultural e seu processo de desenvolvimento institucional ganham um perfil muito próprio e mais lento, cujos caminhos devem ser auscultados com cuidado, para evitar a tendência à importação e transposição direta de teorias, abordagens e metodologias operativas em serviços de saúde e saúde mental.

A partir dessa hipótese, talvez seja possível compreender por que no Brasil apenas uma parcela menor do próprio movimento antimanicomial e dos serviços de atenção psicossocial tenha esboçado iniciativas e estratégias claras na direção do empoderamento de usuários e familiares. Ainda é hegemônica aquela visão mais convencional de que tratamento e cuidado constituem uma prerrogativa dos profissionais e trabalhadores, de que a participação se dá apenas no processo de escuta e de prover informação relativa ao tratamento a usuários e familiares, ou nas assembleias dos serviços, ou ainda no máximo no ativismo direto nos conselhos de controle social. Na mesma direção, no âmbito da vida acadêmica $e$ das práticas de pesquisa avaliativa e interventiva de politicas sociais, poucos núcleos da pesquisa em saúde mental têm procurado desenvolver estratégias de envolvimento, participação e empoderamento de usuários e familiares no próprio processo de pesquisa, tema indicado mais abaixo. 


\section{O envolvimento e o empoderamento de usuários em pesquisa em saúde mental no contexto anglo-saxônico: uma breve revisão descritiva e crítica}

O Reino Unido e os Estados Unidos representam dois casos chaves de forte desenvolvimento de algumas perspectivas acadêmicas e profissionais claramente comprometidas com o empoderamento a partir da década de $1970^{4,13-15}$, como também de um movimento fortemente radical e autonomista de usuários no campo da saúde mental ${ }^{16-19}$. A rápida revisão abaixo dará ênfase a autores distribuídos durante todo este período, tentando mostrar a processualidade e a sofisticação das experiências e análises construídas no campo da pesquisa, a partir dos anos 1980. Além disso, tanto os Estados Unidos quanto o Reino Unido mostram uma forte integração cultural, científica, editorial e política entre eles, bem como uma forte influência nos demais países de língua inglesa, permitindo tratá-los aqui sem distinguir suas especificidades, pelo menos para efeito do presente artigo e de sua necessária concisão. A perspectiva do empoderamento em pesquisa envolveu iniciativas com diversos níveis de envolvimento, participação e empoderamento de usuários e familiares, desde a década de 1980. Um exemplo inicial, ainda em 1984, foi promovido pela ONG inglesa $\mathrm{MIND}^{20}$, uma organização chave no desenvolvimento do movimento autonomista de usuários no país. Ela desenvolveu com a rede de televisão estatal BBC um amplo levantamento da visão dos usuários sobre o consumo crônico de tranquilizantes, mostrando o largo uso de prescrição superdimensionada, os efeitos colaterais e as dificuldades para sua retirada por parte dos usuários. A importância deste tipo de pesquisa, com participação de usuários em todas as fases da investigação, pode ser vista nas suas consequências: uma grande campanha pública sobre o tema pela MIND, com apoio da BBC, com um impacto significativo na cultura, nos serviços de saúde mental e no consumo destes psicofármacos ${ }^{21}$.

Portanto, esse tipo de pesquisa, ou mesmo mecanismos mais informais que valorizam o ponto de vista dos usuários ao nível local, constitui um instrumento importante de empoderamento, revelando suas próprias concepções sobre os problemas da saúde mental, suas experiências e avaliação sobre os vários tipos de serviços e como poderiam concebê-los de acordo com seus interesses e visão de mundo. Também podem fornecer evidências que desafiam os pontos de vista convencionais de planejadores, profissionais e do senso comum, permitindo influenciar a opinião pública, lançar campanhas e reivindicações, e visualizar modos concretos de superar os problemas identificados.

Neste conjunto da literatura anglo-saxônica 'amiga dos usuários' (user friendly) e, ou, comprometida com seu empoderamento, podemos notar diferentes níveis de envolvimento e participação dos usuários de serviços.

Carrick et al. ${ }^{22}$ identificaram três níveis de envolvimento em pesquisas:

- consulta, quando os pesquisadores perguntam a opinião dos usuários;

- colaboração, quando há uma parceria efetiva e divisão do poder entre pesquisadores e usuários;

- projetos controlados pelos usuários, quando usuários e suas organizações decidem envolver profissionais e acadêmicos em aspectos específicos da pesquisa, mas sob seu inteiro controle.

Os autores concluem que o terceiro tipo de pesquisa foi o mais "empoderador", enquanto a consulta representou o menos.

Por sua parte, Hutchinson et al. ${ }^{23}$ e outros autore ${ }^{15}$ indicaram que iniciativas mais simples, tais como dividir com outros usuários uma história pessoal, como sujeitos em uma pesquisa, mesmo sem participar de outras etapas da pesquisa, já podem ser empoderadoras. Beresford e Evans $^{24}$ e Linhorst ${ }^{25}$, em uma abordagem mais complexa, descrevem os parâmetros para a avaliação dos efeitos de empoderamento das pesquisas como um continuum de envolvimento, que vai das mais empoderadoras até as não empoderadoras. Nesta perspectiva, o empoderamento cresce na medida em que os usuários vão gradualmente controlando mais cada aspecto e etapa da pesquisa. Outros autores, tais como Carrick et al.22, são mais pragmáticos, defendendo que "o processo de pesquisa deve empoderar quando possível, ou pelo menos, não deve desempoderar".

Esta indicação de Carrick et al. ${ }^{22}$ nos parece importante, do ponto de vista de uma apropriação transcultural crítica das estratégias de empoderamento no Brasil, pois reforça a nossa direção ética e política de que o processo de empoderamento deve ser relacionado organicamente às características estruturais e conjunturais, bem como às possibilidades reais de empoderamento e seus limites, em cada contexto.

Do ponto de vista das condições e critérios consideradas importantes para o empoderamento de usuários através da pesquisa, nos parece rele- 
vante lembrar aqui, resumidamente, os pontos indicados na revisão realizada por Linhorst ${ }^{25}$ :

a) gestão dos sintomas psiquiátricos: os sintomas psiquiátricos das pessoas envolvidas são geridos no grau necessário para poderem participar de forma plena de sentido de um processo de pesquisa específico;

b) habilidades participativas: a pessoa possui as habilidades necessárias para poder participar de forma plena de sentido de um processo de pesquisa específico;

c) prontidão psicológica: a pessoa tem a confiança, a motivação e a vontade para poder participar de forma plena de sentido de um processo de pesquisa específico;

d) respeito e confiança mútuos: a pessoa com transtorno mental e quaisquer pesquisadores sem transtorno explícito, com os quais ela pode trabalhar, têm o nivel necessário de respeito e confiança mútuos para poder participar de forma plena de sentido de um processo de pesquisa específico;

e) incentivos concretos recíprocos: incentivos concretos existem para a pessoa com transtorno mental para participar em processo de pesquisa e para pesquisadores e outros participantes para trabalhar de forma plena de sentido com ela;

f) disponibilidade de escolhas: a pessoa tem escolhas de processo de pesquisa nas quais pode participar de forma plena de sentido;

g) estruturas e processo de participação: $a$ pessoa tem estruturas e processos através dos quais poderá participar de forma plena de sentido em um processo de pesquisa;

h) acesso a recursos: a pessoa tem acesso aos recursos necessários para participar de forma plena de sentido em um processo de pesquisa;

i) cultura encorajadora: a cultura que envolve o processo de pesquisa é encorajadora de uma participação de forma plena da pessoa com transtorno mental.

Após esta rápida revisão das principais tendências mais engajadas no empoderamento em pesquisas no campo da saúde mental na literatura anglo-saxônica, é fundamental alertar que apenas uma minoria de todo o conjunto das pesquisas avaliativas usam metodologias "amigas do usuário”. A maior parte das avaliações em pesquisas oficiais na Inglaterra e Estados Unidos é capturada pela atual cultura gerencialista, que prioriza a racionalidade financeira, escolhendo metodologias empiricistas e positivistas, como nos desenhos experimentais, que priorizam resultados (e não processo), objetividade, relação custo-eficiência e neutralidade do observador. A maioria dos estudos não questiona quais inte- resses estão sendo enfatizados por um desenho de pesquisa em particular ou por um determinado perfil de definição dos objetivos e resultados, ou ainda por um determinado instrumento e modo de administrá-lo.

Nessa perspectiva, é interessante recuperar um trabalho ainda da década de 1990, mas ainda extremamente relevante, de Perkins e Repper ${ }^{26}$, que avaliaram criticamente as consequências dessas tendências dominantes em pesquisa, salientando os seguintes dilemas principais:

a) Definição de objetivos e resultados dos serviços: diversos autores têm mostrado como os objetivos e os resultados desejáveis de serviços de saúde mental são multidimensionais e dependentes de diferentes pontos de vista, associadas às lutas e relações de poder. Diferentes conjuntos de objetivos e resultados em serviços divergem entre si dadas as diferentes ênfases e perspectivas. Por exemplo, serviços de saúde mental geralmente apresentam resultados com estatísticas convencionais (números de atividades, taxas de admissão e alta, etc.) para notificar as autoridades e para assegurar a continuidade de fundos, com ênfase nos custos e em evitar problemas e polêmicas na comunidade. Porém, esses objetivos diferem daqueles formulados por diferentes grupos de usuários diretos, familiares e profissionais. Todavia, a maior discrepância levanta-se entre profissionais e usuários, na avaliação da efetividade do serviço e na extensão de uma intervenção que seja aceitável para os usuários de serviços. Em nosso ponto de vista, entendemos que a própria tradição de avaliação independente, fortemente enraizada na cultura inglesa e anglo-saxã, deve ser desafiada e rediscutida, na direção de avaliações que explicitassem quais valores, abordagens e interesses seriam priorizados em uma pesquisa. Esta discussão deveria atingir o nível das opções epistemológicas, no qual o debate atual sobre paradigmas científicos e a consequente crítica aos métodos tradicionais empiricistas e neopolitivistas, é essencial ${ }^{27}$.

b) Medindo os resultados: uma questão relacionada à anterior é a de como os objetivos podem ser mensurados. Os instrumentos tradicionais enfatizam as propriedades psicométricas: confiabilidade, validade e sensibilidade das medidas empregadas. Todavia, esse tipo de precisão tende a menosprezar as contradições mostradas no tópico anterior ou em padrões diferentes de covariação. Por exemplo, um nível baixo de melhoramento nos sintomas ou funcionamento social, variáveis clássicas nos estudos de resultados, podem acontecer em paralelo com um entendimen- 
to crescente do usuário sobre seus problemas, o que pode reduzir sentimentos de desespero e angústia, geralmente ignorados. As perspectivas diferentes e os objetivos múltiplos no cuidado da saúde mental exigem medidas e instrumentos de resultados múltiplos e complexos. Como todos eles são planejados pelos especialistas, geralmente refletem suas agendas e preocupações específicas, como, por exemplo, nas escalas convencionais para medir a 'satisfação do paciente'. Um bom contraexemplo a estas escalas, de acordo com Perkins e Repper ${ }^{26}$, é uma construída por usuários para medir o empoderamento entre seus pares em serviços de saúde mental, desenvolvida por uma junta de dez líderes do movimento de usuários nos Estados Unidos, descrita por Rogers et al. ${ }^{28}$, representando a diversidade de pontos de vistas dentro do movimento e adotando os princípios da pesquisa-ação. Contudo, essa escala ainda utiliza um questionário tradicional, enquanto outras metodologias qualitativas realçam a perspectiva dos usuários sobre os serviços: grupos focais, diários mantidos por usuários, relatórios de conselhos de usuários, entre outras indicadas por Perkins e Repper ${ }^{26}$. Além disso, a questão de como administrar tais medidas também é relevante, na medida em que mesmo quando temos pesquisadores independentes, os usuários tendem a agradar os entrevistadores dizendo o que eles gostariam de ouvir. Um modo de evitar isso é envolver os usuários ou o movimento de usuários enquanto pesquisadores, em pesquisa-ação, que tende a levar a informações mais acuradas sobre seus problemas e preocupações. Essa estratégia tem sido adotada por muitas organizações que possuem claro compromisso com o movimento de usuários.

c) A natureza complexa e heterogênea da clientela, de suas dificuldades e dos serviços: no campo da saúde mental, é extremamente difícil avaliar a efetividade de uma única intervenção de outras, de forma isolada das demais, ou ainda as contribuições relativas de seus diferentes componentes. Além disso, a maior parte dos serviços ocidentais tendem a integrar agências estatais, do Terceiro Setor e privadas, propondo mais desafios para a avaliação efetiva dos serviços. A maioria dos estudos tende a examinar um determinado conjunto de intervenções e ignorar todos os outros, excluindo assim as interações entre o alvo em avaliação e as outras intervenções.

d) Metodologia e desenho de pesquisa: nesse tópico, Perkins e Repper ${ }^{26}$ revisaram escolhas entre diferentes metodologias de pesquisa, apontando como elas dependem de diferentes pergun- tas, perspectivas e interesses valorizados, e da própria complexidade inerente aos fenômenos mentais. Até mesmo desenhos de pesquisa epidemiológicos tão em voga na Inglaterra, como os estudos duplo-cego com controle randômico, tem sido severamente criticados não somente em seu uso tradicional na avaliação de novas drogas, mas principalmente no momento de estimar resultados de intervenções complexas e dos serviços no campo de saúde mental. Ademais, a maioria das intervenções psicossociais complexas não podem ser de modo algum 'cegas', visto que são altamente dependentes de crenças, expectativas e relacionamentos pessoais diretos. Além disso, o processo de recuperação em saúde mental é longo, e intervenções a curto prazo podem parecer ineficazes e serem abandonadas em favor daquelas com benefícios mais a curto prazo, mas carecendo de efetividade no longo prazo.

$\mathrm{Na}$ nossa opinião, quando nos deparamos com a literatura anglo-saxônica de avaliação de serviços, também é importante salientar a maior ênfase dada ao resultados do que ao processo, o que vai na direção contrária à perspectiva de empoderamento. Esse é um tema particular levantado pela Psiquiatria Democrática italiana, em suas melhores experiências, principalmente no Norte e na parte central do país ${ }^{29}$. Contudo, também existem contraexemplos interessantes na literatura anglo-saxã, como o livro de Townsend ${ }^{30}$. Utilizando a 'etnografia institucional' desenvolvida pela socióloga canadense Dorothy Smith, influenciada pela etnometodologia, feminismo, fenomenologia e ideias marxistas, o livro investiga as contradições entre as intenções conscientes dos trabalhadores de fortalecer o poder dos usuários de serviços de saúde mental e a invisível organização inconsciente de poderes no cotidiano dos serviços, gerando dependência e perda de autonomia por parte dos usuários. A investigação focaliza tanto as boas intenções de profissionais como os processos institucionais através dos quais o empoderamento é anulado:

as tentativas de facilitar a participação são minadas pelos processos de objetificação, prestação individualizada de contas, de tomada de decisão hierárquica, de educação indutora de simulação, de manejo de risco e exclusão, que protegem mas também controlam as pessoas. O significado desta crítica se estende além dos serviços de saúde mental, porque processos semelhantes são utilizados na organização rotineira de poder em educação, seguro-desemprego, transportes e outros setores da sociedade ${ }^{27}$.

Creio que agora podemos nos direcionar para as ideias e as estratégias de empoderamento 
no Brasil, seus desdobramentos no campo em saúde mental, e na pesquisa envolvendo a área.

\section{Desenvolvimento do empoderamento no Brasil e tendências na produção de conhecimento e na pesquisa em saúde mental}

Movimentos mais amplos que incorporam estratégias de empoderamento, mas sem filiação direta à tradição anglo-saxônica

$\mathrm{Na}$ concepção mais genérica de empoderamento que adotamos, como uma interpelação com longa história de tradições na modernidade, suas estratégias podem não se inspirar diretamente no conceito e nas referências teóricas anglo-saxônicas. Assim, no Brasil e em alguns dos países latino-americanos vizinhos, as ideias e as estratégias de empoderamento são identificáveis em movimentos sociais nas últimas décadas em vários campos. As principais referências bibliográficas já foram indicadas em outros trabalhos de nossa autoria ${ }^{4,31}$, e como os autores indicados são facilmente localizados nos sistemas de indexação digital, dispensamos a indicação de referências nesta seção. Entre estas tradições, podemos citar:

a) As tradições do chamado cristianismo de libertação e da teologia da libertação, um amplo movimento social surgido na América Latina e no Brasil na década de 60, envolvendo setores do clero, movimentos laicos, pastorais populares e Comunidades Eclesiais de Base (CEB), com difusão em outros movimentos sociais populares. Os autores mais citados são Gustavo Gutierrez e, no Brasil, Leonardo Boff. Teve seu auge nas décadas de 1980 e 1990, mas ainda mantém um ativismo importante nas classes populares no Brasil.

b) As tradições de educação popular, particularmente inspiradas em Paulo Freire, a partir da década de 1960, e alguns de seus desdobramentos no campo da saúde, como o movimento de educação popular em saúde, cujos principais fundadores no Brasil são Victor Valla, Eymard Mourão Vasconcelos e Eduardo Stotz, com forte atuação em atenção primária em saúde.

c) A estratégia de controle social incorporadas ao SUS e às principais linhas de política social no país, a partir da Constituição de 1988, por meio de conselhos e conferências formados por metade de seus membros por representantes da sociedade civil.

d) As tradições de teatro popular, como o Teatro do Oprimido do brasileiro Augusto Boal, desde a década de 1970. e) As tradições de pesquisa participante e pesquisa-ação, cujos principais representantes no Brasil são Michel Thiollent e a perspectiva de análise institucional.

f) O movimento institucionalista e grupalista, com suas origens principais na França na década de 1970, e forte difusão no Brasil e na Argentina, com inspiração na psicanálise e teorias sociais críticas. Como exemplos, temos a psicossociologia (Anzieu, Enriquez, Kaës), socioanálise (Lapassade e Lourau), esquizoanálise (Deleuze e Gauattari), e o grupo operativo (Pichon-Rivière). No Brasil, têm influência na psicologia social, psicologia comunitária e em saúde mental.

g) O movimento de economia solidária, hoje política oficial no Brasil, inspirado no cooperativismo, com redes de produção, comercialização, capacitação e apoio técnico.

h) A perspectiva de empoderamento no serviço social brasileiro, representado por Vicente Faleiros e pelo autor deste trabalho.

i) O próprio movimento antimanicomial brasileiro e argentino, que, juntamente com o movimento sanitário, são os principais impulsionadores da reforma psiquiátrica nestes países.

\section{Abordagens explícitas de empoderamento no campo da saúde mental no Brasil}

No Brasil, a partir do novo ímpeto gerado pela criação do movimento antimanicomial, em 1987, e da II Conferência Nacional de Saúde Mental, em 1992, iniciamos a implementação dos novos serviços de atenção psicossocial, e em paralelo, a criação de associações de usuários e familiares. Há uma clara preponderância dos profissionais e trabalhadores no ativismo dentro do movimento antimanicomial, como também as organizações de usuários e familiares vêm mostrando um perfil predominantemente misto (usuários, familiares e profissionais), tendo os últimos um papel mais proeminente e regular, em um quadro de organização, bases financeiras e ativismo político em geral bastante fragilizado ${ }^{3,32}$.

Durante a década de 2000, alguns trabalhos ${ }^{3-}$ 5,18 divulgaram ideias de empoderamento mais diretamente inspiradas na tradição anglo-saxônica em saúde/saúde mental e no movimento dos usuários nestes países. Na segunda metade da década, testemunhamos iniciativas piloto com usuários e familiares, integrados à rede de saúde mental, como também projetos de pesquisa, associados à sistematização dos novos dispositivos ou em avaliação de serviços, muitos dos quais em convênios com países anglo-saxões. Na IV Con- 
ferência Nacional de Saúde Mental, em 2010, as propostas destes novos dispositivos foram aprovadas e incorporadas ao seu Relatório. Mesmo que não possamos revisar estas tendências aqui, o tema será tratado em um artigo coletivo neste mesmo número do periódico, e podemos apenas indicar as suas duas direções básicas:

a) Uma tradição de pesquisa avaliativa de programas e serviços em saúde e saúde mental, com base em formas complexas de envolvimento e participação dos usuários do SUS, mesmo com controle mais geral dos profissionais e pesquisadores. Podemos citar o Laboratório de Pesquisas sobre Práticas de Integralidade em Saúde (LAPPIS), coordenado por Roseni Pinheiro (IMSUERJ $)^{33}$, e o núcleo de pesquisa coordenado por Rosana Onocko-Campos (FCM-UNICAMP) ${ }^{34}$.

b) Projetos piloto de experimentação e sistematização de dispositivos de empoderamento em saúde mental, junto à rede de atenção psicossocial, integrados com pesquisa ou com estratégias participativas de produção de conhecimento e avaliação, diretamente inspirados na tradição anglo-saxônica de empoderamento. Aqui podemos citar os trabalhos coordenados por Onocko Campos em torno do GAM (Grupo Autônomo de Medicação) ${ }^{35}$ e por Eduardo Vasconcelos, do Projeto Transversões (ESS-UFRJ), sobre os grupos de ajuda e suporte mútuos em saúde mental $^{36}$.

\section{Considerações finais}

Este artigo abordou as condições históricas de desenvolvimento de estratégias de empoderamen- to de usuários e familiares no campo da saúde mental e seus desdobramentos no campo da pesquisa avaliativa e interventiva em serviços. Dele, podemos deduzir algumas linhas conclusivas mais gerais:

a) Empoderamento constitui uma abordagem ambígua, mas apropriável para a perspectiva emancipatória dos interesses de setores oprimidos em países periféricos e semiperiféricos, desde que sustentado em teorização social/política e projetos históricos mais amplos, e que se diferencie das apropriações conservadoras dos setores dominantes.

b) As abordagens anglo-saxônicas de empoderamento em saúde mental têm um forte caráter autonomista e uma experiência mais longa, associada ao movimento de usuários, e oferecem um amplo espectro de práticas alternativas em saúde mental e em pesquisa avaliativa e interventiva. Sem dúvida alguma, elas têm um enorme potencial de inspirar e fertilizar outros movimentos antimanicomiais e reformistas de outros países.

c) Entretanto, o contexto diferenciado dos países periféricos e semiperiféricos, como o Brasil, condicionam o significado e o potencial das interpelações autonomistas e de empoderamento em nossos países. Assim, os projetos de intercâmbio e nossas experiências de serviços, de ativismo social e político e de pesquisa, que buscam inspiração na tradição anglo-saxônica, devem levar em alta consideração estas características próprias de nossos países, auscultando com cuidado a dinâmica própria que estes projetos vão tomando localmente. 


\section{Referências}

1. Desviat M. A reforma psiquiátrica. Rio de Janeiro: Fiocruz; 1999.

2. Amarante P. Loucos pela vida: a trajetória da reforma psiquiátrica brasileira. Rio de Janeiro: Fiocruz; 1994.

3. Vasconcelos EM, organizador. Abordagens psicossociais. Volume II: Reforma psiquiátrica e saúde mental na ótica da cultura e das lutas populares. São Paulo: Hucitec; 2008.

4. Vasconcelos EM. O poder que brota da dor e da opressão: empowerment, sua história, teorias e estratégias. São Paulo: Paulus; 2003.

5. Vasconcelos EM, Weingarten R, Leme CCCP, Novaes $\mathrm{PR}$, organizadores. Reinventando a vida: narrativas de recuperação e convivência com o transtorno mental. São Paulo, Rio de Janeiro: Hucitec, EncantArte; 2006.

6. World Bank (WB). Empowerment and poverty reduction: a sourcebook. Washington: WB; 2002.

7. Vasconcelos EM. Derechos y empoderamiento de usuarios y familiares en el terreno de la salud mental. Atopos salud mental, comunidad y cultura $2011 ; 11: 23-44$

8. Faoro R. Os donos do poder: formação do patronato político brasileiro. Porto Alegre, São Paulo: Globo, Cia. Editora Nacional; 1975.

9. DaMatta R. Carnaval, malandros e heróis: para uma sociologia do dilema brasileiro. Rio de Janeiro: Guanabara; 1990.

10. Duarte LFD. Da vida "nervosa" da classe trabalhadora. Rio de Janeiro: Zahar; 1986.

11. Vasconcelos EM. Structural issues underpinning mental health care and psychosocial approaches in developing countries: the Brazilian case. In: Ramon S, Willians JE, editors. Mental health at the crossroads: the promise of psychosocial approach. Hants: Ashgate Publishing Limited; 2005. p. 95-107.

12. Vasconcelos EM, Rodrigues J. Organização de usuários e familiares em saúde mental no Brasil. In: Vasconcelos EM, organizador. Desafios políticos do reforma psiquiátrica brasileira. São Paulo: Hucitec; 2010. p. 141-162.

13. Croft S, Beresford P. From paternalism to participation: involving people in social services. London: Open Services Project; 1990.

14. Kemshall H, Littlechild R, editors. User involvement and participation in social care: research informing practice. London, Philadelphia: Jessica Kingsley Publishers; 2000.

15. Linhorst DM. A review of the use and potential of focus groups in social work research. Qualitative Social Work: research and practice 2002; 1(2):563569.

16. Chamberlin J. On our own. London: MIND; 1988.

17. Mowbray CT, Moxley DP, Colleen AJ, Howell LL. Consumers as providers in psychiatric rehabilitation. Columbia: International Association of Psychosocial Rehabilitation Services; 1997.

18. Weingarten R. O movimento de usuários em saúde mental nos Estados Unidos: história, processos de ajuda e suportes mútuos e militância. Rio de Janeiro: Instituto Franco Basaglia, Projeto Transversões; 2001.
19. Stastny P, Lehmann P. Alternatives beyond psychiatry. Berlin, Eugene: Lehmann; 2007.

20. Mind. [site da Internet]. [acessado 2013 jan 3]. Disponível em: www.mind.org.uk

21. Rogers A, Pilgrim D, Lacey R. Experiencing Psychiatry. London: MIND, Macmillan; 1993.

22. Carrick R, Mitchell A, Lloyd K. User involvement in research: power and compromise. J Community Appl Soc Psychol 2001; 11(3):217-225.

23. Hutchinson SA, Wilson ME, Wilson HS. Benefits of participating in research interviews. J Nurs Scholarsh 1994; 26(2):161-164.

24. Beresford P, Evans C. Research and empowerment. Br J Soc Work 1999; 29:671-677.

25. Linhorst DM. Empowering people with severe mental illness: a practical guide. New York: Oxford University Press; 2006.

26. Perkins R, Repper J. Dilemmas in community mental health practice: choice or control. Abingdon; Radcliffe Medical Press; 1998.

27. Vasconcelos EM. Complexidade e pesquisa interdisciplinar: epistemologia e metodologia operativa. Petrópolis: Vozes; 2002.

28. Rogers ES, Chamberlin J, Ellison ML. A consumerconstructed scale to measure empowerment among users of mental health services. Psychiatr Serv 1997; 48(8):11042-11047.

29. Vasconcelos EM. Avaliação de serviços no contexto da desinstitucionalização psiquiátrica: revisão de metodologias e estratégias de Pesquisa. J Bras Psiquiatr 1995; 44(4):169-197.

30. Towsend E. Good intentions overruled: a critique of empowerment in the routine organisation of mental health services. Toronto: University of Toronto Press; 1998.

31. Vasconcelos EM. Abordagens psicossociais. Volume I: história, teoria e prática no campo. São Paulo: Hucitec; 2008.

32. Vasconcelos EM. Dispositivos associativos de luta e empoderamento de usuários, familiares e trabalhadores em saúde mental no Brasil. Vivência 2007; 32:173-206.

33. Pinheiro R, Martins PH, organizadores. Avaliação em saúde na perspectiva do usuário: abordagem multicêntrica. Rio de Janeiro, Recife: CEPES-IMS, UERJ - Abrasco, Ed. Universitária UFPE; 2011.

34. Onocko Campos R, Furtado JP, Passos E, Benevides R, organizadores. Pesquisa avaliativa em saúde mental: desenho participativo e efeitos de narratividade. São Paulo: Hucitec; 2008.

35. Gonçalves LLM. A Gestão Autônoma da Medicação numa experiência com usuários militantes da saúde mental [tese]. Campinas: Unicamp; 2012.

36. Vasconcelos EM. Manual de ajuda e suporte mútuos em saúde mental. Rio de Janeiro, Brasília: Escola de Serviço Social da UFRJ, Ministério da Saúde, Fundo Nacional de Saúde; 2013. No prelo.

Artigo apresentado em 24/04/2013

Aprovado em 15/06/2013

Versão final apresentada em 03/07/2013 